\title{
PARAMETRIC STUDY ON GEOGRID REINFORCED RETAINING WALL SYSTEM
}

\author{
Ms. Radhika Borkar \\ P. G. Student, Department of Civil Engineering \\ Government Engineering College, \\ Aurangabad, Maharashtra, India
}

\begin{abstract}
Reinforced earth retaining is a type of retaining wall which can bear the lateral earth pressure which is made up of backfill, stressed geosynthetic and facing system. "Zornberg J.G, (2001) in their work emphasis that- Traditional soil reinforcing techniques involve the use of continuous geosynthetic inclusions such as geogrids and geotextiles". The acceptance of geosynthetics in reinforced soil construction has been triggered by a number of factors, including aesthetics, reliability, simple construction techniques, good seismic performance, and the ability to tolerate large deformations without structural distress. Examples include advances in reinforced soil design for conventional loading (e.g. validation of analysis tools), advances in design for unconventional loading (e.g., reinforced bridge abutments), and advances in reinforcement materials (e.g., polymeric fiber reinforcements)."R.D. Haltzs (2001) in their work emphasize -Geosynthetics as soil reinforcement used for embankments on soft foundations, steep slopes, and for the backfills of retaining walls and abutments". Emphasis is on the materials properties of the geosynthetics required for design and construction. Reinforced soil retaining walls (RSW) are widely used in geotechnical engineering practice throughout the world. Reinforced soil walls have been constructed using steel strip reinforcement geogrids, geosynthetics, and geocomposite. Geosynthstics manufactured from advanced polymer materials became popular as an alternative to steel strip reinforcement in reinforced soi1 walls.
\end{abstract}

Keywords - Geotextiles, Geogrids, Geosynthetic, Reinforcement materials, Retaing wall

\section{INTRODUCTION}

Retaining wall

A retaining wall is a structure designed and constructed to resist the lateral pressure of soil, when there is a desired change in ground elevation that exceeds the angle of response of the soil. Retaining wall is a cantilever type wall, which is a freestanding structure without lateral support at its top. These are cantilevered from a footing and rise above the grade on one side to retain a higher level grade on the opposite side.

\author{
Dr. Mrs. Shubhada S. Koranne \\ Associate Professor, Department of Civil Engineering \\ Government Engineering College, \\ Aurangabad, Maharashtra, India
}

The walls must resist the lateral pressures generated by loose soils or, in some cases, water pressures.

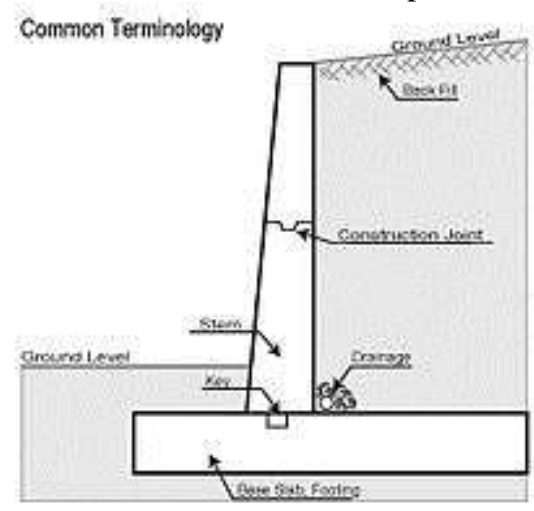

Fig 1. Cantilever Retaining Wall

Geogrids:

Geogrids are polymeric products formed by joining intersecting ribs. The geosynthetic material, geogrids, is polymeric products which are formed by means of intersecting grids. The polymeric materials like polyester, high-density polyethylene and polypropylene are the main composition of geogrids. These grids are formed by material ribs that are intersected by their manufacture in two directions: one in the machine direction (md), which is conducted in the direction of the manufacturing process. The other direction will be perpendicular to the machine direction ribs, which are called as the cross-machine direction (CMD). Geogrids are mainly made from polymeric materials, typically polypropylene (PP), high density polyethylene (HDPE) and polyester (PET). The high demand and application of Geogrids in construction are due to the fact that it is good in tension and has a higher ability to distribute load across a large area. 


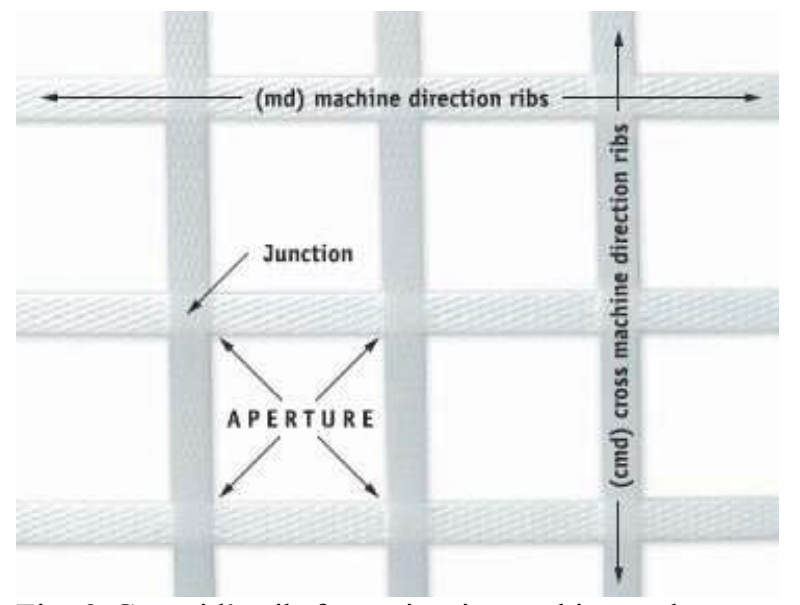

Fig. 3 Geogrid's rib formation in machine and cross machine directions of manufacturing process

Based on direction of stretching during manufacture

Uniaxial geogrids

Biaxial Geogrids

Uniaxial Geogrids

These geogrids are formed by the stretching of ribs in the longitudinal direction. So, in this case, the material possesses high tensile strength in the longitudinal direction than on the transverse direction.

Biaxial Geogrids

Here during the punching of polymer sheets, the stretching is done in both directions. Hence the function of tensile strength is equally given to both transverse and longitudinal direction.
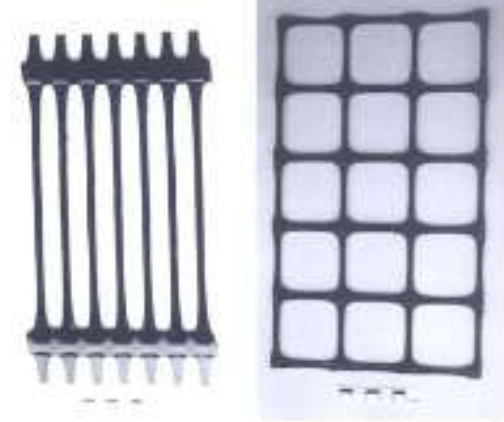

Fig 3. Uniaxial and Biaxial Geogrids manufactured by the method of extrusion

\section{HEADINGS}

Objectives of Study:

1. To evaluate the influence of system properties, such as soil, geogrid and interface stress-strain parameters and loading conditions on the overall wall response as indicated by performance parameters such as the maximum settlement of the wall and maximum tension in the geogrid.

2. To account for scale effects that would occur when predicting the response of large-scale reinforced systems based on small-scale test data.
3. To evaluate the effect of different types of geogrid reinforcement and/or backfill soils.

4. To explore appropriate means of analytically modeling creep and geogrid degradation effects.

5. To evaluate and verify the long-term performance of MSE walls through experiments, supplemented with analysis methods.

6. To incorporate the above findings in the current design guidelines and to develop a computer program for designing and analyzing MSE walls under creep conditions.

\section{EXPERIMENTAL WORK-}

\section{Materials-Soil}

For the model tests cohesion less, dry and clean standard sand is used as the foundation material. The particle size of sand used for the test was passing through600 micron sieve.

\section{Geogrid}

The glass fiber geogrid is cho osen as research material because the strength of glass fiber geogrid is lower than other model grids; it meets the need of scaled model test.

TGSG 1515

Aperture Size $-1.8 \mathrm{~mm}$ X $1.8 \mathrm{~mm}$

Color - white

\section{Steel Box}

The test setup consists of a strong mild steel (MS) box having $720 \mathrm{~mm}$ in length, $220 \mathrm{~mm}$ in breadth and $600 \mathrm{~mm}$ in height (internally). Four handle are provided on top side for holding purpose.

\section{Polythene}

The front walls were coated with a thin layer of white petroleum grease and polythene sheet strips of $60 \mathrm{~mm}$ width were placed to reduce boundary friction effects.

Footing-

Size Upper plate- $140 \mathrm{~mm}$ - rectangular size Height $-100 \mathrm{~mm}$

Lower plate $-20 \mathrm{~mm}$ square size Material - steel

\section{Wall facing-}

The facing of reinforced wall is done with the gravel gabion wall along with wrap around facing.

Gravel gabion wall is made at 90 degree to the surface.

The spacing of grids is maintained using the gravel gabion of two different sizes. For spacing $5 \mathrm{~cm}$ - gabion height $5 \mathrm{~cm}$ Spacing $7.5 \mathrm{~cm}$ - gabion height $7.5 \mathrm{~cm}$

\section{INDENTATIONS AND EQUATIONS}

Height of Mould, $\mathrm{H}=15.24 \mathrm{~cm}$

Diameter of Mould, $\mathrm{D}=15.24$

Volume of Mould $=(\pi / 4) \times \mathrm{D}^{\wedge} 2 \times \mathrm{H}$

$$
=2780.006 \mathrm{~cm}^{\wedge} 3
$$

Density of Soil $=3700 / 2780.006=1.331 \mathrm{gm} / \mathrm{cc}$

For maximum density- 
Wt. of soil $=10250-5920$

$$
=4330 \mathrm{gm}
$$

Density $=4300 / 27000=1.558 \mathrm{gm} / \mathrm{cc}$

Density at Field condition, $\square_{\mathrm{df}}=1.5 \mathrm{gm} / \mathrm{cc}$

Relative Density $=[1.558(1.5-1.333)] /[1.5(1.558-1.333)]$ $\times 100$

$$
=77.09 \%
$$

$\%$ of compaction $=\square_{\mathrm{df}} / \square_{\max } \times 100$

$$
=(1.5 / 1.558) \times 100
$$

$=96.28 \%$

\section{FIGURES AND TABLES}

Summary of test results-

\begin{tabular}{|c|c|c|}
\hline Soil Property & Loose & Dense \\
Sand & Sand \\
&
\end{tabular}

\section{Unit weight}

15

17

2. Ø in Plane

39

45

Strain

Condition

\begin{tabular}{|c|c|c|c|c|}
\hline & $\begin{array}{c}\text { First } \\
\text { Sample }\end{array}$ & $\begin{array}{c}\text { Second } \\
\text { Sample }\end{array}$ & $\begin{array}{c}\text { Third } \\
\text { Sample }\end{array}$ & $\begin{array}{c}\text { Fourth } \\
\text { Sample }\end{array}$ \\
\hline $\begin{array}{c}\text { Normal } \\
\text { Stress } \\
(\mathrm{KN} / \mathrm{m} 2)\end{array}$ & 27 & 54 & 82 & 112 \\
\hline
\end{tabular}

Normal stress on soil-

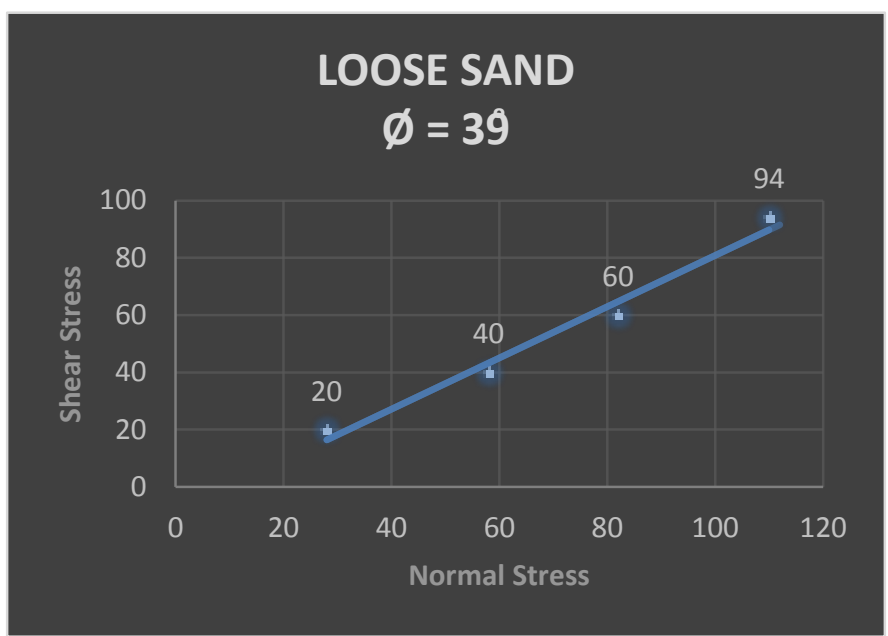

Graph -1

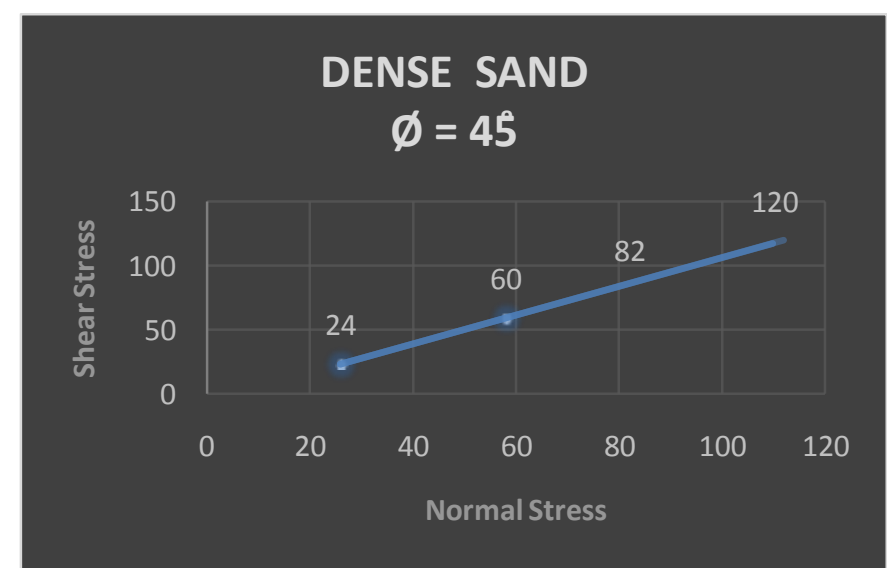

Graph -2 
International Journal of Engineering Applied Sciences and Technology, 2019

Vol. 4, Issue 3, ISSN No. 2455-2143, Pages 332-337

Published Online July 2019 in IJEAST (http://www.ijeast.com)

\begin{tabular}{|c|c|c|c|}
\hline LOAD & UNREINFORCED & TYPE A & TYPE B \\
\hline 0 & 0 & 0 & 0 \\
\hline 0.5 & 1.9 & 0.88 & 0.62 \\
\hline 1 & 3.8 & 1.74 & 1.23 \\
\hline 1.5 & 5.7 & 2.67 & 1.85 \\
\hline 2 & 6.8 & 3.58 & 2.56 \\
\hline 2.5 & 7.6 & 4.43 & 3.13 \\
\hline 3 & 8.6 & 6.22 & 3.71 \\
\hline
\end{tabular}

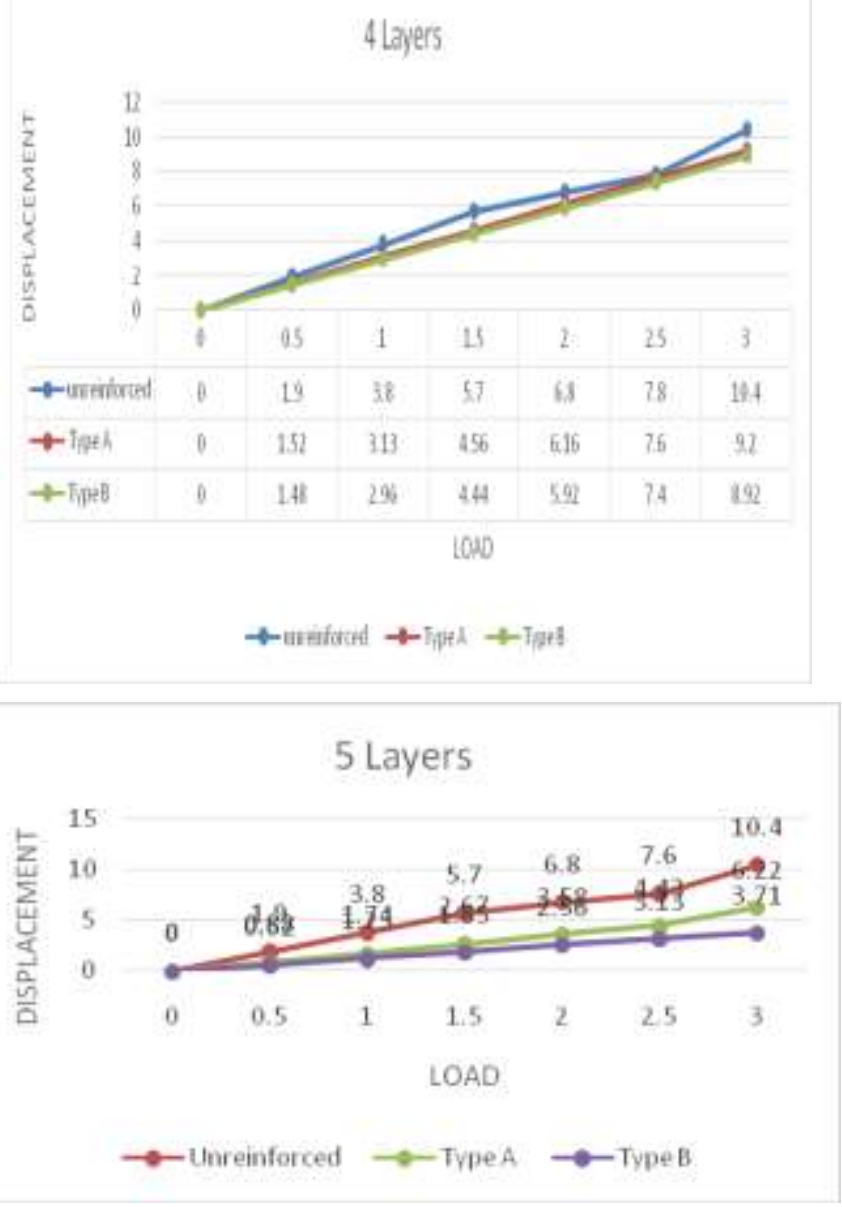

\begin{tabular}{|c|c|c|c|}
\hline Load & Unreinforced & Type A & Type B \\
\hline 0 & 0 & 0 & 0 \\
\hline 0.5 & 1.9 & 1.635 & 1.535 \\
\hline 1 & 3.8 & 3.31 & 3.1 \\
\hline 1.5 & 5.7 & 5 & 4.61 \\
\hline 2 & 6.8 & 6.54 & 6.23 \\
\hline 2.5 & 7.6 & 8.25 & 7.75 \\
\hline 3 & 10.4 & 9.81 & 9.21 \\
\hline
\end{tabular}
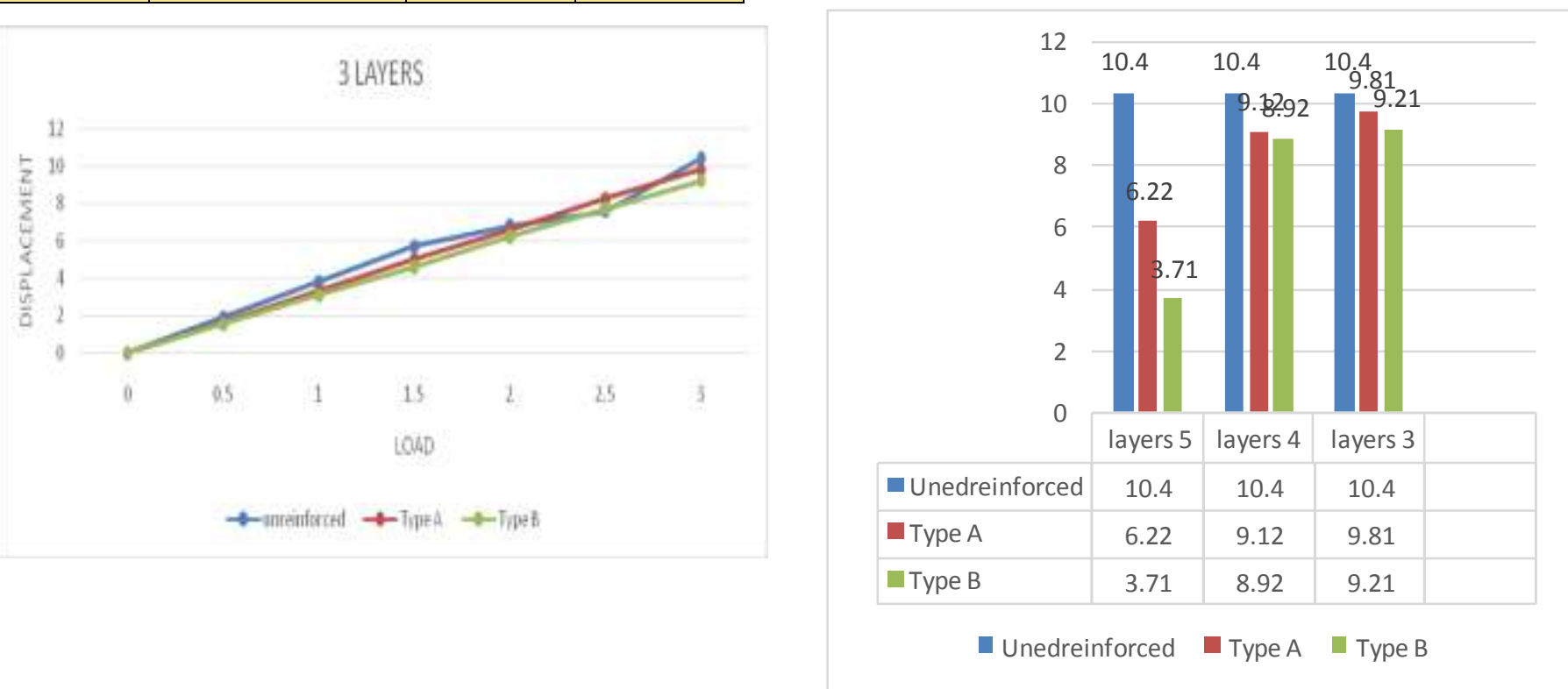


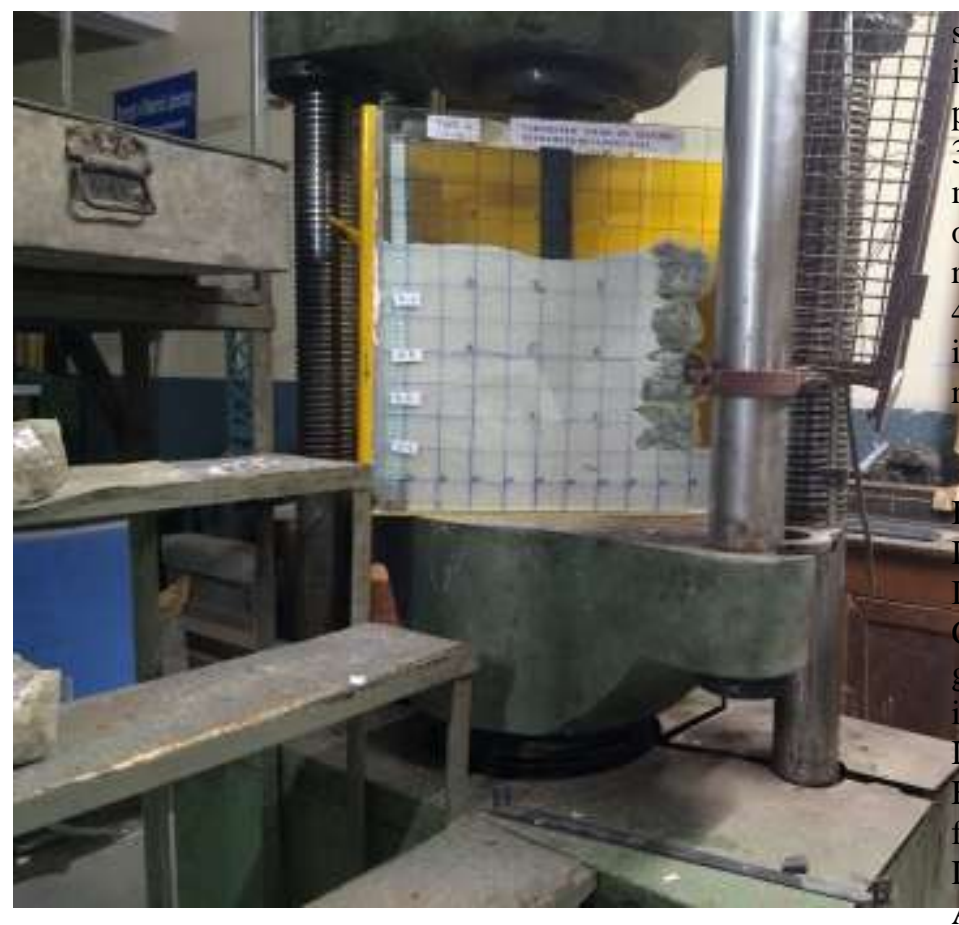

To ensure a high-quality product, diagrams and lettering MUST be either computer-drafted or drawn using India ink. Figure captions appear below the figure, are flush left, and are in lower case letters. When referring to a figure in the body of the text, the abbreviation "Fig." is used. Figures should be numbered in the order they appear in the text. Table captions appear centered above the table in upper and lower case letters. When referring to a table in the text, no abbreviation is used and "Table" is capitalized.

\section{CONCLUSION}

In this study, reinforced retaining wall with different reinforcement length, spacing, layers and aperture were studied by scaled model tests. The measured data of Universal Testing Machine (UTM) in the form of load vs. displacement values and graph were obtained. This study also analyzed the data obtained from experimental monitoring to investigate the influence of reinforcement length, spacing, and number of layers and aperture size of geogrid on the deformation of reinforced retaining walls. The following conclusions were obtained-

1. AS the number of layers of geogrids are increaseure the strength and durability of the structure gets increased. Thus the Number of layers of reinforcement in the GRS walls is directly proportional to the strength of the structure.

2. In the same reinforcement spacing condition the measured deformation of geogrid reinforced retaining wall was increased as the load on the footing plate is increased. A Soil mass reinforced by closely spaced reinforcement will likely to behave as a coherent mass. The spacing $.1 \mathrm{H}$ and $.15 \mathrm{H}$ is studied As the spacing is decreased strength of structure is increased. Thus spacing and strength of structure are inversely proportional to each other.

3. It is observed through the study that overturning may be the most critical mode of failure with short reinforcement length of $.3 \mathrm{H}$ to $.4 \mathrm{H}$, while sliding governs the wall with reinforcement length of $.6 \mathrm{H}$ to $.7 \mathrm{H}$.

4. It is analysed that the geogrids of larger aperature size has ideal results of durability and displacement values until the rupture point.

\section{ACKNOWLEDGEMENTS}

rexpress my heartfelt gratitude and deepest sense of regards to Dr. Mrs. Shubhada S. Koranne, Associate Professor, Department of Civil Engineering, Government Engineering abad (M.H.), and India under her able kind supervision the present piece of uld be completed. I am grateful to Dr. R. M. Deptt. of Civil Engineering, Goverenment ollege, Aurangabad, (M.H.) for providing y research work. I express my sincere thanks to Dr. P.B. Murnal, Principal, Government Engineer College, Aurangabad, (M.H.) for valuable help and co-operation. My
thanks are to my research colleagues Mr. Mahesh S. Hudekar, Mr. Manoj S. Sadafale for their kind co-operation.

\section{REFERENCE}

1) Curtis.R.L, Chouery V.L et al.(1988) ," Geogrid Reinforced Soil Retaining Wall On Compressible Soils", International Conference On Case Histories In Geotechnical Engineering .

2) Karpurapu R, BATHURST R.J (1995), "BEHAVIOUR OF GEOSYNTHETIC REINFORCED SOIL RETAINING WALLS USING THE FINITE ELEMENT METHOD" Computers And Geotechnics 17.

3) Randeniya. R, Valsangkar.A.J, et al (1994), "PERFORMANCE OF A GEOGRID REINFORCED W ALLSTONE Retaining W ALL SYSTEM", Calgary, Canada.

4) Ochiai H., Otani J. et al. (1996), "The Pull - Out Resistance Of Geogrids In Reinforced Soil" ,Geotextiles And Geomambrane .

5) Allen T.M, Bathurst R.J (2014), "Performance Of An 11 M High Block-Faced Geogrid Wall Designed Using The K-Stiffness Method" Can. Geotech. J. Vol. 51.

6) Holtz.R.D (2001), “Geosynthetics for Soil Reinforcement", 9th Spencer J. Buchanan Lecture, November.

7) Bathurs.R.J, Miyata.Y et al.(2008), "Refinement Of K-Stiffness Method For Geosynthetic Reinforced Soil Walls", Geosynthetics International. 
8) Bathurst.R.J, Allen T. (2009), "Reinforcement Loads in Geosynthetic Walls and the Case for a New Working Stress Design Method".

9) Hatami K., Bathurst R.J, et al, (2001) "Static Response of Reinforced Soil Retaining Walls with Nonuniform Reinforcement", The International Journal of Geomechanic.

10) Allen, T.M., Bathurst R.J, et al, (2013) "Comparison of Working Stress and Limit Equilibrium Behavior of Reinforced Soil Walls", Geotechnical Special Publication.

11) Graeme D.S, Rowe R.K, et al, (2005) "Design and Behavior of a Geosynthetic Reinforced Retaining Wall and Bridge Abutment on a Yielding Foundation", Geotextiles and Geomembranes 23.

12) Bathurst R.J, Miyata.Y. et al. (2010) , "Facing Displacements In Geosynthetic Reinforced Soil Walls",Earth Retention Conference 3 .

13) Kibria G., Hossain S. et al (2014) "Influence of Soil Reinforcement on Horizontal Displacement of MSE Wall", American Society of Civil Engineers.

14) .Kawarmura T. And T.Hirai, (2007),"Confining Effect In Geogrid Reinforced Soil Related To Soil Dilatancy."

15) Scotland, N. D \& Horgan M.G, (2012) "Serviceability Limit State Design in Geogrid Reinforced Walls and Slopes, International Geosynthetics Society. 